\title{
Planificación y gestión del agua en España, en la actualidad
}

\author{
María SOTELo PÉREZ ${ }^{1}$ \\ Instituto Universitario de Ciencias Ambientales (IUCA/UCM) \\ Departamento de Análisis Geográfico Regional y Geografía Físisca (UCM) \\ Grupo de Investigación: "Desarrollo y Gestión Ambiental del Territorio" \\ maria.sotelo.perez@ucm.es \\ Ignacio SOTELO PÉREZ \\ ignaciosoteloperez@ucm.es
}

Recibido: 19 de mayo de 2014

Enviado a evaluar: 23 de mayo de 2014

Aceptado: 28 de julio de 2014

\section{RESUMEN}

A la hora de tratar la gestión compleja del recurso hídrico en España debemos tener en cuenta que existe una gran variedad de legislaciones que regulan el abastecimiento, depuración y consumo del agua. Por ello, en el presente artículo analizaremos de manera pormenorizada el Marco Legal Internacional, el Marco Legal de España, las Confederaciones Hidrográficas y los Organismos de Cuencas, amén de incidir en el estudio del Progama A.G.U.A., la Estrategia Española de Desarrollo Sostenible y las nuevas evaluaciones de las políticas integrales de la Unión Europea como es el "Fitness Check Freshwater Policy Instruments".

Palabras clave: Planificación, gestión, agua, normativa, legislación.

\section{Planning and management of water in Spain, present day}

\begin{abstract}
When dealing with the complex management of water resources in Spain must be aware that there are a variety of laws that regulate the supply, purification and water consumption. Therefore, in this article we will discuss in detail the International Legal Framework Legal Framework of Spain, the River Basin and Basin Organizations, in addition to influencing the study of "Progama A.G.U.A", the Spanish Sustainable Development Strategy and the new comprehensive assessments of EU policies such as the "Fitness Check Freshwater policy Instruments".
\end{abstract}

Key words: Planning, management, water, regulations, legislation.

${ }^{1}$ Investigadora en formación. Becaria FPU (Formación del Profesorado Universitario), Ministerio de Educación, Cultura y Deporte. 


\section{Planification et gestion de l'eau en Espagne, actuellement}

\section{RÉSUMÉ}

Lorsqu'il se agit de la gestion complexe des ressources en eau en Espagne doit être conscient qu'il ya une variété de lois qui régissent l'approvisionnement, la purification et la consommation d'eau. Par conséquent, dans cet article nous allons discuter en détail le cadre juridique cadre juridique international de l'Espagne, le bassin de la rivière et Organismes de Bassin, en plus d'influencer l'étude de "Progama A.G.U.A", l'espagnol Stratégie de développement durable et le nouveau évaluations globales des politiques de l'UE tels que la «remise en forme Vérifier Instruments Politique d'eau douce".

Mots clés: Planification, la gestion, l'eau, la réglementation, la législation.

\section{PRIMERA APROXIMACIÓN}

El deterioro del medio ambiente a través de la contaminación de las aguas, de forma concreta, es tan grave e intenso como sutil. En tan sólo unos años, buena parte de la red hidrológica de los países desarrollados podemos afirmar que se está convirtiendo en auténticas cloacas a cielo abierto. El agua de no pocos ríos se ha convertido en un elemento destructor de la vida y de la salud. Todo ello sin olvidarnos que las consecuencias de las acciones degradantes ejercidas sobre las aguas pueden llegar a grandes extensiones territoriales. La contaminación de las aguas de un río afecta a todos los ribereños ubicados aguas abajo; afecta a la vida de todo el curso del río, entre otros. La denominada planificación hidrológica en España, a partir de las directrices de la Directiva Marco del Agua para el período 2009-2015 tendría que haber concluido en los momentos actuales. A pesar de todo, varias son las cuestiones que empiezan a presentársenos, en lo que al estado de nuestras aguas se refiere. Nuestros ríos, humedales, acuíferos, lagos y aguas de transición y costeras, y los ecosistemas asociados a ellos, están muy deteriorados (FNCA, 2014). Las evaluaciones realizadas han determinado que más del $50 \%$ de todas nuestras aguas están en mal estado, bien por deterioro de su estado ecológico -por extracciones excesivas, alteraciones de los cauces, "represamiento" de las aguas, etc.-, bien por contaminación química. Como consecuencia hemos puesto en peligro la capacidad de estos ecosistemas de seguir proporcionándonos el agua en la cantidad y calidad que necesitamos.

A la hora de tratar la gestión compleja del recurso hídrico en España debemos tener en cuenta que existe una gran variedad de legislaciones que regulan y gestionan el abastecimiento, depuración y consumo del agua. Para ello podemos hacer una distinción entre el Marco Legal Internacional, el Marco Legal de España, las Confederaciones Hidrográficas y los Organismos de Cuencas, así como incidir en el estudio del Progama A.G.U.A. y la Estrategia Española de Desarrollo Sostenible. Cobra de esta forma relativa importancia el tratar del "Marco Institucional".

El Marco Institucional, de la gestión del agua en España, se conforma por entes de carácter público y privado que interactúan con el fin primario de abastecer de bienes y servicios relacionados con el recurso hídrico para, de este modo, satisfacer las 
necesidades ilimitadas de la población (consumo directo e indirecto del recurso hídrico). Este marco institucional complejo en el que conviven elementos con competencias concurrentes e incluso compartidas haciendo necesario una coordinación - no siempre fácil - entre distintas instituciones.

Cuadro 1. Organigrama Marco Institucional de la Gestión del Agua en España.

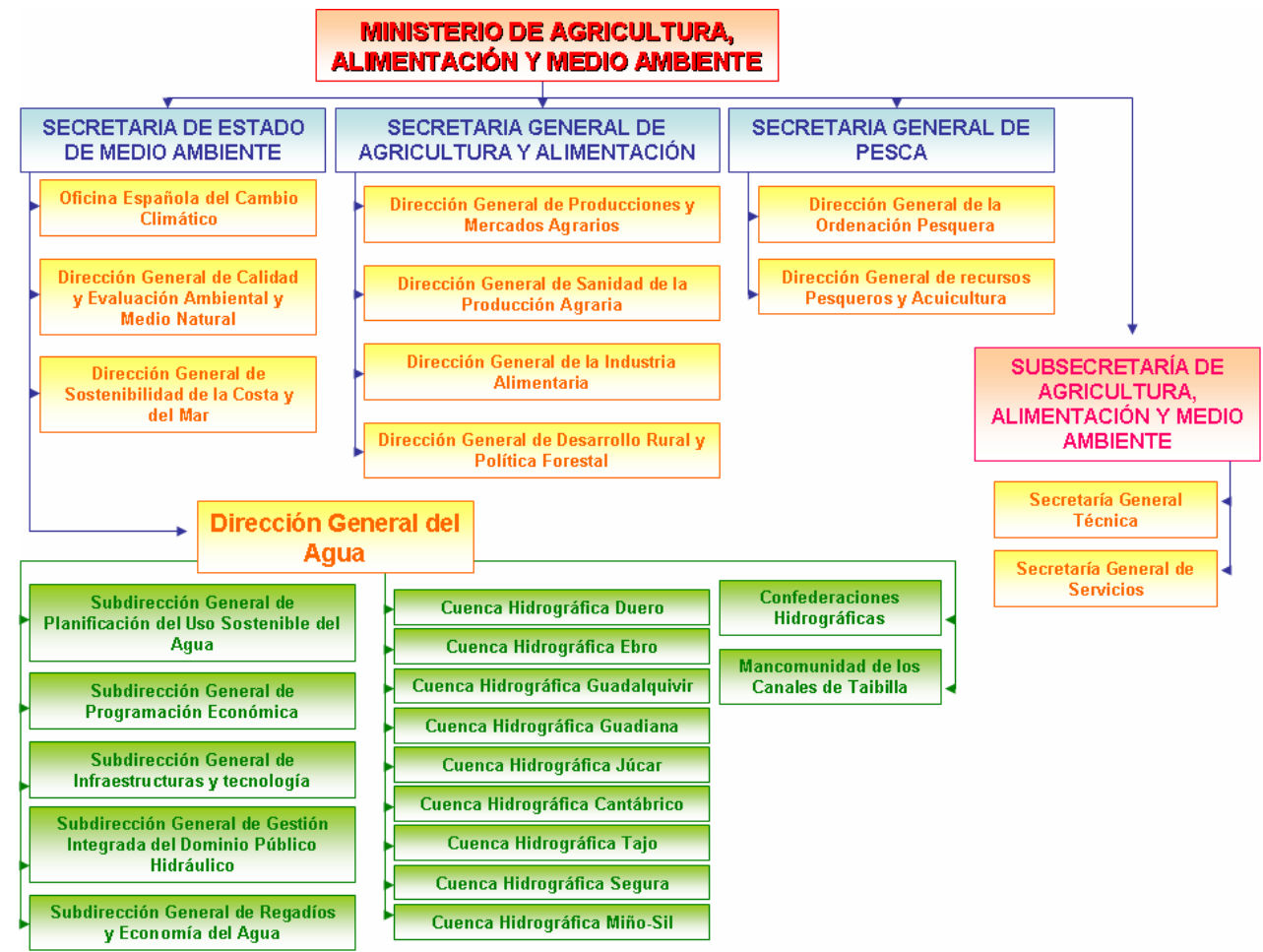

Fuente: Elaboración propia, a partir del Ministerio de Agricultura, Alimentación y Medio Ambiente.

Actualmente, la autoridad nacional encargada de la gestión del recurso hídrico es el Ministerio de Agricultura, Alimentación y Medioambiente ${ }^{2}$ (ver cuadro 1). Dicha gestión la lleva a cabo mediante la Dirección General del Agua, la cual se encuentra adscrita a la Secretaria de Estado de Medio Ambiente y, cuyas funciones principales son:

${ }^{2}$ Ejerce la tutela de las sociedades estatales reguladas por el art. 132 del Texto Refundido de la Ley de Aguas, aprobado por Real Decreto Legislativo 1/2001, de 20 de julio. 
1) La elaboración del Plan Hidrológico Nacional; de la normatividad sobre los Planes de Cuenca y de su coordinación con los planes sectoriales;

2) El sistema de información de los recursos hídricos;

3) La coordinación de los planes de emergencia;

4) La inspección y el control de seguridad de las infraestructuras hidráulicas;

5) El establecimiento de los criterios para la conservación de los acuíferos;

6) El impulso y fomento de las actividades de depuración y reutilización de las aguas depuradas y, en general, de todas las medidas destinadas a favorecer el ahorro del agua.

7) Los planes y proyectos de interés general de ordenación agraria, urbana, industrial y de aprovechamientos energéticos o de ordenación del territorio en tanto afecten sustancialmente a la planificación hidrológica o a los usos del agua.

Dentro de la Secretaría del Estado (ver cuadro 1), encontramos distintas entidades encargadas de la regulación, control y buen desarrollo de las actividades estipuladas por la Secretario General del Agua. Por un lado, la Secretaría se subdivide en cinco subdirecciones;

\section{a. Subdirección General de Planificación del Uso Sostenible del Agua}

Es la encargada, fundamentalmente, de elaborar el seguimiento y revisión del Plan Hidrológico Nacional bajo el principio de sostenibilidad, por lo que se creó el Consejo Nacional del Agua ${ }^{3}$, reseñado en la Ley de 1985, es el órgano consultivo superior con funciones de planificación hidrológica en España. Estas consisten fundamentalmente en informar preceptivamente sobre el proyecto de Plan Hidrológico Nacional y los Planes Hidrológicos de Cuenca entre otros.

Por otro lado, dentro de la Dirección Genera del Agua encontramos a los organismos de cuenca, los cuales se constituyeron en Cuencas Hidrográficas según lo previsto en el art. 19 de la Ley de Aguas de 1985 (art. 21 del Texto Refundido). Estos organismos se encargan de la administración del dominio público hidráulico mediante diferentes tipos de figuras como la subasta de cuotas -también denominados mecanismos de mercado-, cuotas de vertidos, concesiones administrativas... Con todo ello, la Administración pública -Estado, Administración Autonómica y Entidades Locales- se encarga de potenciar las actividades económicas ligadas al recurso hídrico.

${ }^{3}$ Artículo 13 del Real Decreto 927/1988, de 29 de julio 


\section{b. Subdirección General de Programación Económica}

Le corresponde la elaboración, ejecución, control y seguimiento del proyecto de presupuesto de la Dirección General, la tramitación y gestión de contratos de obras y, la programación de los proyectos financiables con fondos europeos.

\section{c. Subdirección General de Infraestructuras y Tecnologías}

Principalmente, tiene la función de realización, supervisión y control de proyectos de explotación y conservación del dominio público hidráulico y del patrimonio de las infraestructuras hidráulicas de sus competencias. De igual modo, se encarga de la inspección y control de la seguridad del proyecto y de desarrolla competencias del departamento derivadas de la aplicación de la Directiva Marco del Agua.

\section{d. Subdirección General de Gestión Integrada del Dominio Público Hidráulico}

Desempeña las funciones de vigilancia, control y seguimiento de los niveles de calidad del agua continental y subterránea, controlando aquellas actividades que son susceptibles de provocar la contaminación o degradación del dominio público hidráulico. A su vez, otorga o cancela concesiones de aguas y autorizaciones de vertidos y, elabora estudios con el fin de determinar los criterios del régimen económico-financiero de la utilización del dominio público hidráulico.

En cuanto a las administraciones públicas autonómicas, encontramos bajo la supervisión de la Dirección de la Secretaría de Estado de Medio Ambiente, a través de la Dirección General del Agua los Organismos Autonómicos de;

\section{La Mancomunidad de los Canales del Taibilla:}

Es un organismo autónomo de carácter comercial ${ }^{4}$, creada por Real Decreto Ley de 4 de octubre $1927^{5}$, encargada de abastecer de agua potable (mediante la captación, tratamiento, conducción y almacenamiento en depósitos de reserva) a $11.000 \mathrm{~km}^{2}$

\footnotetext{
${ }^{4}$ Art. $4^{\mathrm{o}}$.1.b) de la anterior Ley General Presupuestaria), adaptado a Organismo autónomo de los previstos en el artículo 43.1 de la Ley 6/1997 (LOFAGE) por la Ley 50/1998 de Acompañamiento a los Presupuestos Generales del Estado para 1999 (artículo 60).

${ }^{5}$ Artículo $1^{\circ}$ de la Ley de 27 de Abril de 1946: "... y tendrá a su cargo los estudios y redacción de los proyectos y la ejecución de las obras e instalaciones de captación, regulación, conducción y depósitos de arranque de las distribuciones interiores para el abastecimiento de agua potable a la Base Naval y Puerto de Cartagena, de las poblaciones cuyos municipios formen parte de la Mancomunidad y de los establecimientos y entidades de carácter estatal situadas en la misma región que éstos, así como la conservación, explotación, vigilancia y administración de las referidas obras e instalaciones en la parte que sean comunes a dichos abastecimientos..."
} 
pertenecientes a las Comunidades Autónomas de Castilla-La Mancha, Murcia y Valencia y, a las Confederaciones Hidrográficas del Segura y del Júcar (abasteciendo así a más de 2,5 millones de habitantes de las provincias de Murcia, Alicante y Albacete, fundamentalmente).

\section{Las Confederaciones Hidrográficas: Estudiadas más adelante.}

Por último, los Ayuntamientos y Entidades Locales son fundamentales en la gestión del agua, sobre todo en lo referente a la prestación de servicios finales a los usuarios como es el abastecimiento de agua potable, el saneamiento y la depuración. Sin embargo, en los últimos años, esta gestión no sólo dependen de la Administración Pública sino que el sector privado participa de dicha actividad - prestar servicios finales a los usuarios- mediante concesiones administrativas. Un ejemplo de ello lo encontramos en las Comunidades de Usuarios y los concesionarios con derechos al uso privativo del agua.

\section{MARCO LEGAL INTERNACIONAL}

El cuerpo normativo sobre la política europea del agua se ha visto fuertemente incrementado a partir de 2006. Como señala el profesor Juan Urbano (2014), la proliferación de actos se refiere a un esfuerzo universalizador e integrador, propio del enfoque ecosistémico. Por una parte pone en el centro del problema el recurso hídrico y su conservación en sí mismo, interesándose por todos los procesos y ecosistemas en los que el agua tome parte. Por otra parte, se acomete un esfuerzo centrípeto que tiende a encajar en un uno toda la normativa relativa al agua que se ha generado en distintos momentos.

Desde esta perspectiva, podemos hablar de un antes y un ahora de la "Directiva Marco del Agua".La primera norma que aún están en vigor y tiene por objeto la calidad del agua es la Directiva relativa a la calidad de las aguas de baño (Directiva 76/160/CEE). Esta Directiva estará en vigor hasta el 31 de diciembre de 2014, fecha en que dará paso a la Directiva 2006/7/CE, relativa a la gestión de la calidad de las aguas de baño. La mencionada Directiva 76/160/CEE tiene como objetivos: la reducción y prevención de la contaminación de las aguas de baño e informar a los ciudadanos europeos sobre el grado de contaminación de las mismas. Se establecen criterios mínimos de calidad a través de sustancias índice de contaminación, fijando sus valores límite. Asimismo se establece un procedimiento de seguimiento y control con una frecuencia mínima de muestreo y un método de análisis e inspección (Urbano, J. 2014).

La nueva Directiva 2006/7/CE declara su complementariedad con la Directiva Marco del Agua y establece como su objetivo principal la protección del medio ambiente y la salud humana. Entre las novedades de su contenido se pueden citar: la calificación de las zonas de baño a partir de la declaración de las mismas por los Estados Miembros; la vigilancia de nuevos indicadores de calidad como son las algas; la información a los ciudadanos y su participación en la información y gestión; y la 
vinculación de la calidad de las zonas de baño con la gestión integral de la cuenca hidrográfica. No debemos olvidar que la Conferencia Ministerial de Francfort (1988) vio la necesidad de aumentar la protección de la calidad de las aguas, lo que se concretó en la aprobación de normas relativas al tratamiento de las aguas residuales urbanas (Directiva 91/271/CEE) y a la protección de las aguas contra la contaminación producida por nitratos utilizados en la agricultura (Directiva 91/676/CEE). La primera pretende armonizar a escala comunitaria las medidas de tratamientos de las aguas residuales urbanas, y de algunos sectores industriales, tanto en su recogida, tratamiento como vertido. La segunda (Directiva sobre Nitratos) tiene como objetivo la protección de la calidad de las aguas superficiales y subterráneas en Europa evitando la contaminación por nitratos de origen agrario. Con estas normas se pretendía acometer las dos principales causas identificadas de contaminación del agua. Ambas tienen como objetivo la calidad de las aguas y la disminución de la contaminación a través de la limitación de los focos contaminantes, se centran en el control y reducción de las principales causas de contaminación (Urbano, J. 2014)

De una u otra forma, destacar que la regulación nacional de los recursos hídricos está condicionada por las normas emanadas de la Unión Europea. Además de regulaciones relativas a aspectos concretos (como sustancias peligrosas, intercambios de información, agua potable...), la principal norma es la Directiva Marco del Agua (DMA 2000/60/CE) entró en vigor el 22 de diciembre del 2000. Es el basamento jurídico sobre el que la Unión Europea está construyendo una política de aguas sostenible, como norma es innovadora y ambiciosa en sus objetivos, compleja en su contenido y aplicación, e integradora y participativa en sus métodos ${ }^{6}$. La DMA surge como respuesta a la necesidad de unificar las actuaciones en materia de gestión de agua en la Unión Europea, ya que se pretende abordar de manera eficiente y eficaz los problemas dimanados de la perdida de biodiversidad de los ecosistemas hídricos europeos, aunando así las diversas directivas existentes en Europa para abordar las diversas problemáticas vinculadas a los usos del recurso hídrico (consumo doméstico, de ocio, industrial,...) y su principal objetivo es coordinar y armonizar la mayoría de los instrumentos existentes en el ámbito de la legislación nacional y comunitaria sobre el uso del agua, estableciendo un marco común para la protección del recurso natural.

En España, fue transpuesta al ordenamiento jurídico español mediante el artículo 129 de la Ley 62/2003 de 30 de diciembre de medidas fiscales, administrativas y del orden social que modifica el texto refundido de la Ley de Aguas, aprobado por Real Decreto Legislativo 1/2001, de 20 de julio. En 2007, en relación con la aplicación de la DMA, en España se dictan varios Reales Decretos ${ }^{7}$. En primer lugar el Real

${ }^{6}$ La Calle Marcos, A. (2009) La adaptación española de la Directiva Marco del Agua. Fundación Nueva Cultura del Agua. Sevilla.

${ }^{7}$ Red Ambiental de Asturias. Gobierno del Principado de Asturias. Principios de la Directiva Marco del Agua. http://www.asturias.es 
Decreto 125/2007, de 2 de febrero, por el que se fija el ámbito territorial de las demarcaciones hidrográficas, definiendo su ámbito según la normativa europea y la nacional. Así se entiende por demarcación hidrográfica la zona terrestre y marina compuesta por una o varias cuencas hidrográficas vecinas y las aguas de transición, subterráneas y costeras asociadas a dichas cuencas (según lo dispuesto en el RDL $1 / 2001$, artículo 16 bis 1$)$.

La Directiva Marco del Agua (DMA) (Directiva 60/2000/CE) supone un giro radical y, de alguna manera, se puede decir que la política del agua en Europa toma cuerpo. Se pone en el centro la protección de las aguas y su potencial ecológico, a través de: la prevención, protección y mejora de los ecosistemas acuáticos y de los terrestres asociados; el uso sostenible del agua; el control de la contaminación y la reducción de vertidos de sustancias peligrosas tanto en aguas superficiales como subterráneas; y las medidas para paliar inundaciones y sequías. El resultado de estas actuaciones será el suministro de agua en cantidad y calidad suficiente. Cuando la Directiva habla de aguas comprende a las superficiales, las de transición, las costeras y las subterráneas, dándole un sentido integrador y haciendo patente la interrelación de los impactos entre ellas (Urbano, J. 2014).

En la DMA se fijan los objetivos medioambientales de calidad para cada tipo de masa de agua, descrito por indicadores biológicos, hidromorfológicos y físicoquímicos. Se debe realizar un estudio de impacto de las actividades humanas y un análisis económico del uso del agua, que servirán para caracterizar la demarcación hidrográfica. La comparación entre el estudio de impacto y el objetivo medioambiental llevará a plantear un Programa de medidas eficaz. Los programas de medidas de una demarcación y otras actuaciones para el cumplimiento del resto de la normativa europea sobre el agua se contienen en un Plan Hidrológico de Cuenca (PHC), que será la herramienta de trabajo e inversión para lograr un potencial ecológico adecuado. Los Planes debieron estar aprobados en 2009 y se planteaba la primera revisión en 2015 y posteriormente, cada 6 años.

Inmediatamente después de la aprobación de la DMA se vio que su aplicación iba a ser difícil y ambiciosa en todos los estados miembros. Los directores generales del agua de los estados miembros, se mostraron de acuerdo en la necesidad de fijar una Estrategia Común de Aplicación (Common Implementation Strategy -CIS-) que contuviese visiones y planteamientos comunes a los problemas, guías técnicas y buenas prácticas, experiencias imitables y evitables y evitase duplicidades. Para redactar los documentos que compondrían la CIS se constituyeron 10 Grupos de Trabajo (Working Group) y 3 Foros de Expertos (Expert Advisory Fora).

En 2003 se reestructuró el sistema de trabajo, centrando los temas de interés, agrupando grupos de trabajo y simplificando la cadena de toma de decisiones y jerarquización del trabajo. El resultado de estas actuaciones se contiene en el documento WFD Common Implementation Strategy-Progress and Work Programme 2003/2004. A partir de este documento se fijan 3 Grupos de Trabajo (Estado Ecológico, Gestión Integrada de Cuencas Hidrográficas, Aguas Subterráneas e Información -Ecological Status, Integrated River Basin Management, Groundwater 
and Reporting-), que agruparán a los 10 anteriores y se concreta para cada uno de ellos -mediante fichas- los temas, objetivos y programas de trabajo.

El grupo de trabajo sobre Estado Ecológico reúne a los grupos anteriores de: intercalibración, control y seguimiento, condiciones de referencia y clasificación de aguas interiores y aguas marinas. Mantuvo las actividades de: a) intercalibración, para asegurar que la evaluación de la calidad ecológica es comparable entre los Estados Miembros y que las clases definidas como buen estado ecológico por la DMA son consistentes; $\mathrm{y}$ b) elaboración de la guía de clasificación, que fijara un acuerdo común y un enfoque práctico sobre cómo utilizar los parámetros físico-químicos para clasificar el estado y potencial ecológico.

El grupo de trabajo de Gestión Integrada de Cuencas Hidrográficas reunió a los grupos de: temas económicos, cuencas hidrográficas piloto, humedales y gestión integrada de cuencas hidrográficas. Mantuvo las actividades sobre: a) humedales, para la redacción de una guía horizontal sobre humedales que identifique su papel en los programas de medidas y sus requerimientos en la DMA; b) prueba integrada en las cuencas hidrográficas piloto, que asegure la coherencia de las distintas guías para el desarrollo a largo plazo de los Planes Hidrológico de Cuenca; c) integración de los temas económicos horizontales, haciendo viable la aplicación de los documentos guía de temas económicos elaborados; y d) orientación metodológica de los temas económicos, que desarrolló directrices prácticas para que los estados miembros y los países candidatos puedan evaluar la recuperación de costes incluyendo los costes ambientales (Urbano, J. 2014).

La orden de trabajo sobre aguas subterráneas fue presentada en octubre de 2003 y el Foro de Asesores Expertos continuó su trabajo hasta que la Comisión presentara la propuesta de Directiva de aguas subterráneas. El grupo de trabajo sobre Información mantuvo las actividades de: a) elaboración de una guía para informar en el marco de la DMA, con objeto de armonizar la información y datos que se deben comunicar entre los estados miembros y la Comisión; y b) el estado del medio ambiente (denominado SoE), cuya misión es establecer cómo los datos sobre el estado del medio ambiente existente en los estados miembros pueden utilizarse más efectivamente para definir el estado del medio ambiente en Europa y como se relacionan con otras políticas.

El trabajo normativo es esencialmente distinto al técnico-científico de los Grupos de trabajo y los Foros de Asesores, pero no cabe duda de que los resultados de de los trabajos del CIS se han vertido y han impulsado a las Directivas y Comunicaciones que en materia de agua aparecieron desde 2004. Concretamente la Directiva relativa a la protección de las aguas subterráneas contra la contaminación y el deterioro (Directiva 2006/118/CE) y la Directiva sobre los Estándares de Calidad Ambiental en la política del agua (EQS) (Directiva 2008/105/CE) se consideran productos directos -"hijas"- de los trabajos de la Estrategia Común de Aplicación (CIS).

La estructura de la Directiva Marco del Agua podemos dividirla en tres apartados en los que se recogen consideraciones iniciales, el articulado propio de la legislación y un conjunto de anexos fundamentales. El primero de los apartados está compuesto por cincuenta y tres consideraciones de tipo programático, conceptuales, de referencia 
científica y técnica..., que tiene como finalidad dar a conocer los motivos de su promulgación y, por ende sus objetivos y la importancia de los mismos. En el segundo apartado encontramos un conjunto de veintiséis artículos que constituyen el núcleo fundamental de la puesta en funcionamiento de la propia Directiva, gracias los cuales se articulan las distintas acciones llevadas a cabo por las distintas Administraciones que estipula la legislación. Y, por último, un tercer apartado en el que se incluyen once anexos en los que se introducen tablas y definiciones aclaratorias.

Atendiendo a los objetivos de la presente Directiva podemos hacer distinción entre objetivos principales y objetivos intermedios. Dentro de los primeros, como objetivos principales, la Directiva Marco del Agua establece un marco de protección de las aguas superficiales continentales, las aguas de transición, las aguas costeras y las aguas subterráneas que ${ }^{8}$ :

1. Prevenga todo deterioro adicional y proteja y mejore el estado de los ecosistemas acuáticos $\mathrm{y}$, con respecto a sus necesidades de agua, de los ecosistemas terrestres y humedales directamente dependientes de los ecosistemas acuáticos.

2. Promueva un uso sostenible del agua basado en la protección a largo plazo de los recursos hídricos disponibles; a través del "principio de no deterioro" y de conseguir el "buen estado" para el año 2015.

3. Tenga como objetivo una mayor protección y mejora del medio acuático, entre otras formas mediante medidas específicas de reducción progresiva de los vertidos, las emisiones y las pérdidas de sustancias prioritarias, y mediante la interrupción o la supresión gradual de los vertidos, las emisiones y las pérdidas de sustancias peligrosas prioritarias.

4. Garantice la reducción progresiva de la contaminación del agua subterránea y evite nuevas contaminaciones.

5. Contribuya a paliar los efectos de las inundaciones y sequías, y que contribuya de esta forma a:

5.1.Garantizar el suministro suficiente de agua superficial o subterránea y evitar nuevas contaminaciones.

5.2.Reducir de forma significativa la contaminación de las aguas subterráneas.

5.3.Proteger las aguas territoriales y marinas.

5.4.Lograr los objetivos de los acuerdos internacionales pertinentes, incluidos aquellos cuya finalidad es prevenir y erradicar la contaminación

${ }^{8}$ Directiva 2000/60/CE del Parlamento Europeo y del Consejo, de 23 de octubre de 2000, por la que se establece un marco comunitario de actuación en el ámbito de la política de aguas DO L327 22/12/2000. 
del medio ambiente marino, mediante medidas comunitarias previstas en el apartado 3 del artículo 16.

Además permite establecer unos objetivos medioambientales homogéneos entre los Estados Miembros para las masas de agua, siendo estos clasificados como objetivos intermedios:

1. Establecer medidas concretas para la reducción de vertidos, emisiones y pérdidas de sustancias prioritarias y la interrupción o supresión gradual de vertidos, emisiones y pérdidas de las sustancias peligrosas prioritarias. Las sustancias prioritarias se identifican en el Anejo X de la Directiva. Un subconjunto de ellas son las sustancias peligrosas prioritarias (tóxicas, persistentes y bioacumulables).

2. Garantizar la reducción progresiva de la contaminación del agua subterránea y su uso sostenible.

3. Contribuir a paliar los efectos de inundaciones y sequías.

El cumplimento de los objetivos y el desarrollo de todas estas actividades, quedarán plasmadas mediante la elaboración y ejecución de los planes hidrológicos en cada demarcación hidrográfica y la puesta en marcha de los programas de medidas básicas y complementarias, que se coordinarán e integrarán en los planes hidrológicos y deberán llevarse a cabo por las distintas administraciones competentes con la finalidad de alcanzar los objetivos medioambientales.

A su vez, para la consecución de estos objetivos medioambientales la DMA establece la obligación de realizar una serie de actividades interdependientes:

1. Establecer un "buen estado del agua" (Art. 4);

2. Un estudio de las características de la demarcación, de las repercusiones de la actividad humana en el estado de las aguas y un análisis económico de los usos del agua (Art. 5);

3. la creación de un registro de zonas protegidas (Art. 6);

4. el establecimiento de programas de seguimiento del estado de las masas de agua (Art. 8);

5. la aplicación de la recuperación de los costes de los servicios relacionados con el agua (Art. 9),

6. el establecimiento de las medidas necesarias para asegurar la participación activa de todas las partes interesadas, etc.

Con todo ello, tras estructurar y clasificar los objetivos fundamentales de la Directiva Marco del Agua debemos destacar la idea de que, dicha Directiva, incide particularmente en los aspectos medioambientales, por encima de todos los demás; puesto que su objetivo primario es establecer un marco que garantice la protección y gestión de las aguas y, a su vez, establecer conexiones con otras normas relativas a la conservación de la naturaleza. Desde este punto de vista puede entenderse que forma 
parte de una política ambiental global en el marco de la Comunidad Europea, a la que se constituye en cabecera del derecho comunitario de aguas, integrando anteriores normativas y directivas, todas ellas de aplicación parcial.

Si analizamos cada uno de los artículos mencionados, observamos que, el artículo 4 es uno de los más importantes de la Directiva, puesto que expone que especifica cuales son los objetivos medioambientales a conseguir y poner en práctica los programas de medidas especificados en los planes hidrológicos de cuenca, tanto para las aguas subterráneas como las superficiales y las zonas protegidas, los Estados miembros "habrán" de aplicar "las medidas necesarias" para prevenir el deterioro, en términos generales.

Uno de los aspectos importantes es la consideración no solo de las aguas continentales sino también de otras, introduciendo el concepto de "masas de agua" que incluye (Art. 6 DMA):
a. Aguas continentales: superficiales ${ }^{9}$ y subterráneas ${ }^{10}$
b. Aguas de transición
c. Aguas costeras
d. Masas de aguas artificiales
e. Masas de aguas muy modificadas.

La clasificación de las masas de agua se realiza atendiendo a distintos criterios como son su situación (superficial o subterránea), su tipología (río o lago, de transición o costera, acuífero o acuíferos), su origen (natural, artificial, o muy modificada), su uso (utilizadas para la captación de agua potable, de uso recreativo y de baño) y su estado (óptimo, muy bueno, bueno, aceptable, malo y muy malo).

Se trata, pues de incluir todas las masas de agua, a excepción de las marinas, algo que parece lógico desde el punto de vista de la unicidad del ciclo hidrológico, ero que, hasta ahora, no se había plasmado en ninguna legislación ${ }^{11}$.

Para todas estas masas de agua se establece el concepto de "estado de las aguas" (art.4 DMA), relacionado con su "estado ecológico. La consideración de este estado ya no depende de los contaminantes presentes en las mismas, sino de su estado ecológico global. Como segunda característica principal es la introducción, por primera vez de forma clara en la legislación comunitaria, del concepto de división física en vez de administrativa a la hora de planificar los recursos hídricos, con la definición de Demarcación Hidrográfica. Es de sobra conocido que en España, la consideración de cuenca hidrográfica natural a efectos de planificación y gestión de las aguas data de hace más de un siglo, cuando se crearon los primeros sindicatos de

\footnotetext{
${ }^{9}$ Artículo 2.10 de la Directiva 2000/60/CE.
}

${ }^{10}$ Artículo 2.12 de la Directiva 2000/60/CE. 
cuenca y de forma más específica desde 1926 con la creación de las primeras Confederaciones Hidrográficas.

El concepto de Demarcación presenta sin embargo algunas y sustanciales diferencias con las actuales Cuencas Hidrográficas españolas, derivadas fundamentalmente de la consideración de las aguas de transición y de las aguas costeras, fuera hasta ahora del ámbito de actuación de los Organismos de cuenca, especialmente estas últimas. Además, estas Demarcaciones pueden incluir, o no, varias cuencas hidrográficas (En España, cada Demarcación tiene una sola Cuenca mientras que en Europa existe un elevado número de cuencas hidrográficas enmarcadas dentro de varios países). Otra característica relevante es la consideración que se le da a la "recuperación de costes de los servicios relacionados con el agua" (artículo 9) ${ }^{12}$.

La Directiva Marco del Agua (Directiva 2000/60/CE), implica a los Estados miembros de la UE en la aplicación de mecanismos que consigan la internalización, hasta el 2010, de los costes sociales y ambientales del consumo de agua que actualmente se presentan, al no tomarse en cuenta su agotamiento y su deterioro en las decisiones de los particulares acerca del agua, por no existir un precio para dicho recurso natural (sin lugar a dudas las consecuencia de la aplicación de la Directiva se están notando en estos últimos años).

\section{${ }^{12}$ Art. 9 Directiva 2000/60/CE}

1.Los Estados miembros tendrán en cuenta el principio de la recuperación de los costes de los servicios relacionados con el agua, incluidos los costes medioambientales y los relativos a los recursos, a la vista del análisis económico efectuado con arreglo al anexo III, y en particular de conformidad con el principio de que quien contamina paga.

Los Estados miembros garantizarán, a más tardar en 2010:

a. que la política de precios del agua proporcione incentivos adecuados para que los usuarios utilicen de forma eficiente los recursos hídricos y, por tanto, contribuyan a los objetivos medioambientales de la presente Directiva,

b.una contribución adecuada de los diversos usos del agua, desglosados, al menos, en industria, hogares y agricultura, a la recuperación de los costes de los servicios relacionados con el agua, basada en el análisis económico efectuado con arreglo al anexo III y teniendo en cuenta el principio de que quien contamina paga.

Al hacerlo, los Estados miembros podrán tener en cuenta los efectos sociales, medioambientales y económicos de la recuperación y las condiciones geográficas y climáticas de la región o regiones afectadas.

2. Los Estados miembros incluirán en los planes hidrológicos de cuenca información sobre las medidas que tienen la intención de adoptar para la aplicación del apartado 1 y que contribuyan al logro de los objetivos medioambientales de la presente Directiva, así como sobre la contribución efectuada por los diversos usos del agua a la recuperación de los costes de los servicios relacionados con el agua. (./..) 
En esta línea de actuación, el artículo 9 de la Directiva considera la importancia de tener en cuenta el principio de recuperación de costes y que los precios sirvan como incentivo para mejorar la eficiencia en el uso del agua así de esta forma coadyuvar a la consecución de los objetivos ambientales que propugna. De esta forma a la función básica de los precios del agua, que es la de cubrir los costes de los servicios, se le añade un nuevo papel como instrumento para proteger la calidad del agua y con ello contribuir a proteger también la salud de los ecosistemas y al desarrollo sostenible.

Cuadro 2. Mecanismos de recuperación de costes (art. 9 Directiva Marco del Agua)

\begin{tabular}{|c|c|c|c|c|c|}
\hline Servicio & Agentes & $\begin{array}{c}\text { Usuario/ } \\
\text { Contaminador }\end{array}$ & $\begin{array}{c}\text { Costes } \\
\text { Financieros }\end{array}$ & $\begin{array}{c}\text { Costes } \\
\text { Ambientales }\end{array}$ & $\begin{array}{l}\text { Mecanismos } \\
\text { de } \\
\text { recuperación } \\
\text { de costes }\end{array}$ \\
\hline $\begin{array}{l}\text { Embalses y } \\
\text { trans porte en } \\
\text { alta (aguas } \\
\text { superficiales) }\end{array}$ & $\begin{array}{l}\text { Organismos de } \\
\text { cuenca, } \\
\text { sociedades } \\
\text { estatales y otros } \\
\text { agentes. }\end{array}$ & $\begin{array}{l}\text { Doméstico, } \\
\text { Industrial y } \\
\text { Agrícola }\end{array}$ & $\begin{array}{c}\text { Costes de } \\
\text { inversión, } \\
\text { mantenimiento y } \\
\text { conservación }\end{array}$ & $\begin{array}{c}\text { Daños } \\
\text { ambientales } \\
\text { provocados por } \\
\text { la captación y el } \\
\text { transporte de } \\
\text { agua }\end{array}$ & $\begin{array}{l}\text { Canon de } \\
\text { Regulación y } \\
\text { Tarifa de } \\
\text { utilización de } \\
\text { agua }\end{array}$ \\
\hline $\begin{array}{l}\text { Extracción de } \\
\text { Aguas } \\
\text { Subterr áneas }\end{array}$ & $\begin{array}{c}\text { Organismos de } \\
\text { cuence, } \\
\text { colectivos de } \\
\text { riego y usuarios } \\
\text { privados } \\
\text { (autoservicios) }\end{array}$ & $\begin{array}{l}\text { Doméstico, } \\
\text { Industrial y } \\
\text { Agrícola }\end{array}$ & $\begin{array}{c}\text { Costes de } \\
\text { inversión, } \\
\text { mentenimiento y } \\
\text { conservación }\end{array}$ & $\begin{array}{l}\text { Daños } \\
\text { ambientales } \\
\text { provocados por } \\
\text { la extracción de } \\
\text { agua de los } \\
\text { acuíferos }\end{array}$ & $\begin{array}{l}\text { Fijados por los } \\
\text { Ayuntamientos } \\
\text { y Comunidades } \\
\text { de Regantes }\end{array}$ \\
\hline $\begin{array}{c}\text { Abastecimiento } \\
\text { Urbano }\end{array}$ & $\begin{array}{l}\text { Ayuntamientos, } \\
\text { Mancomunidades } \\
\text {. Comunidades } \\
\text { Autónomas y } \\
\text { otros. }\end{array}$ & $\begin{array}{l}\text { Doméstico e } \\
\text { Industrial }\end{array}$ & $\begin{array}{l}\text { Costes de } \\
\text { inversión, } \\
\text { mentenimiento y } \\
\text { conservación }\end{array}$ & $\begin{array}{c}\text { Daños } \\
\text { ambientales } \\
\text { provocados por } \\
\text { el uso y la } \\
\text { potabilización del } \\
\text { agua }\end{array}$ & $\begin{array}{l}\text { Tarifas del } \\
\text { Servicio de } \\
\text { Abastecimiento }\end{array}$ \\
\hline $\begin{array}{l}\text { Recogida y } \\
\text { tratamiento de } \\
\text { aguas residuales } \\
\text { urbanas }\end{array}$ & $\begin{array}{l}\text { Ayuntamientos, } \\
\text { Mancomunidades } \\
\text { Comunidades } \\
\text { Autónomas y } \\
\text { otros. }\end{array}$ & Agrícols & $\begin{array}{c}\text { Costes de } \\
\text { inversión, } \\
\text { mantenimiento y } \\
\text { conservación }\end{array}$ & $\begin{array}{c}\text { Daños } \\
\text { ambientales } \\
\text { provocados por } \\
\text { el uso del agua y } \\
\text { la contaminación } \\
\text { difusa }\end{array}$ & $\begin{array}{c}\text { Derrame o } \\
\text { parte } \\
\text { proporcional de } \\
\text { costes } \\
\text { incurridos }\end{array}$ \\
\hline $\begin{array}{l}\text { Distribución de } \\
\text { aguas de riego }\end{array}$ & $\begin{array}{l}\text { Comunidades de } \\
\text { regantes y otros } \\
\text { colectivos de } \\
\text { riego }\end{array}$ & $\begin{array}{l}\text { Doméstico e } \\
\text { Industrial }\end{array}$ & $\begin{array}{c}\text { Costes de } \\
\text { inversión, } \\
\text { mantenimiento y } \\
\text { conservación }\end{array}$ & $\begin{array}{c}\text { Daños } \\
\text { ambientales por } \\
\text { la contaminación } \\
\text { del sgua y los } \\
\text { residuos }\end{array}$ & $\begin{array}{c}\text { Tases de } \\
\text { Alcantarillado y } \\
\text { Canon de } \\
\text { Saneamiento }\end{array}$ \\
\hline $\begin{array}{l}\text { Control de } \\
\text { vertidos }\end{array}$ & $\begin{array}{c}\text { Organismos de } \\
\text { cuenca }\end{array}$ & $\begin{array}{l}\text { Doméstico e } \\
\text { Industrial }\end{array}$ & $\begin{array}{l}\text { Costes de } \\
\text { inversión, } \\
\text { mantenimiento y } \\
\text { conservación }\end{array}$ & $\begin{array}{c}\text { Daños } \\
\text { ambientales } \\
\text { provocados por } \\
\text { los vertidos a la } \\
\text { naturaleza }\end{array}$ & $\begin{array}{c}\text { Canon de } \\
\text { Control de } \\
\text { Vertidos y otras } \\
\text { figuras }\end{array}$ \\
\hline
\end{tabular}

Fuente: Elaboración propia, a partir de Maestu, J. y Villar, A.

Mediante la aplicación de los Principios de "Plena Recuperación de los Costes" de los servicios asociados al agua (incluidos los costes medioambientales) del de "Quien Contamina, Paga", la propia Directiva Marco pretende que los Estados miembros implanten medidas o políticas interiores que generen los incentivos adecuados para 
que los usuarios de este recurso (sectores agrícola, industrial o doméstico), lo utilicen de forma eficiente, económica y ambientalmente.

La Directiva relativa a la evaluación y gestión de los riesgos de inundación (Directiva 2007/60/CE) y la Directiva Marco sobre la Estrategia Marina (Directiva 2008/56/CE) no son resultado de los trabajos del CIS, pero están fuertemente vinculadas al proceso de aplicación de la DMA. Sobre todo la Directiva de evaluación y gestión de los riesgos de inundación, ya que los planes de gestión de riesgos de inundación deberán coordinarse con los Planes Hidrológicos de Cuenca -PHC-.

En noviembre de 2012 se presentó el tercer Informe de Aplicación de la DMA: Planes Hidrológicos de Cuenca 2009-2015 (COM (2012) 670 final). El informe se centra en evaluar los PHC remitidos por los estados miembros en cumplimiento de la DMA. Los PHC, junto con los Programas de Medidas de Acompañamiento, son la piedra angular de la DMA, ya que recogen el estado ecológico de las aguas, sus presiones y el programa de medidas para alcanzar el objetivo medioambiental deseado (Urbano, J. 2014).

El informe revisa los 124 planes recibidos -ninguno español-, en el momento de publicación, y emite una serie de mensajes clave y recomendaciones. Si los PHC son la herramienta principal de aplicación de la DMA, las conclusiones y directrices aportadas en el informe se convierten en la concreción práctica de la política del agua en la UE. El informe (COM (2012) 670) fue remitido de la Comisión al Parlamento Europeo y al Consejo en la misma fecha (14-11-2012) que se remitió el Water Blueprint.

\section{EL “FITNESS CHECK FRESHWATER POLICY INSTRUMENTS” (FCF)}

Asimismo, las estrategias y comunicaciones relativas a la vulnerabilidad del recurso hídrico están relacionadas con la puesta en práctica de la DMA, ya que algunas directrices propuestas por la Comunicación relativa a la escasez del agua y las sequías o el Libro Blanco para la adaptación climática, animan a que en los Planes Hidrológicos de Cuenca se incluyan planes de gestión de la sequía.

La proliferación de Directivas hizo que los Directores Generales del Agua de los Estados Miembros que trataron la redacción del WB, desde el principio, tuvieran claro que el WB no debería ser otra Directiva. La CIS ha fortalecido la idea de unidad entre la DMA y el resto de las Directivas relativas al agua, sobre todo de las aparecidas desde 2006 (Urbano, J. 2014).

Dentro de la política legislativa "inteligente" de la UE la Comisión anunció dentro de su Programa de Trabajo de 2010 (European Commission, 2010) la intención de "revisar todo el corpus legislativo en determinadas políticas, a través de "Fitness Checks". Con el objetivo de identificar cargas excesivas, solapamientos, vacíos legales, inconsistencias y/o medidas obsoletas que hayan podido aparecer con el tiempo." Una de las áreas piloto elegidas fue Medio Ambiente y dentro de ella la protección del agua dulce en la UE. Esta actuación se denomina: el Fitness Check Freshwater Policy Instruments (FCF) (European Commission, 2012). 
El Fitness Check incluye entre la materia de su estudio a:

1. Directiva Marco del Agua. Directiva 2000/60/CE

1. Directiva relativa a la protección de las aguas subterráneas contra la contaminación y el deterioro. Directiva 2006/118/CE

2. Directiva sobre los Estándares de Calidad Ambiental en la política del agua (EQS), Directiva 2008/105/CE

3. Directiva relativa al tratamiento de las aguas residuales urbanas, Directiva 91/271/CEE

4. Directiva relativa a la protección de las aguas contra la contaminación producida por nitratos utilizados en la agricultura, Directiva 91/676/CEE.

5. Directiva relativa a la evaluación y gestión de los riesgos de inundación. Directiva 2007/60/CE

6. Directiva relativa a la calidad de las aguas destinadas al consumo humano Directiva 98/83/CEE

7. Directiva relativa a la calidad de las aguas de baño, Directiva 76/160/CEE

8. Directiva Marco sobre la Estrategia Marina, Directiva 2008/56/CE

El Fitness Check pretende también un análisis adaptativo y cualitativo de la normativa y en este sentido, en materia de agua, se incluye entre la documentación a valorar:

1. La Comunicación sobre escasez de agua y sequía y su informe anual de seguimiento. COM (2007) 414.

2. El Documento de Trabajo sobre Cambio Climático, Agua, Costas y Temas Marinos. SEC (2009) 386.

Así, pues, como señala el profesor Juan Urbano (2014) de lo anteriormente expuesto se colige que si el FCF es el sustrato en el que se desarrolla el WB -como propone la Comisión-, el WB es el Plan de Acción que anuda toda la política del agua de la UE a corto y medio plazo. Se podría decir que al poner la DMA en el centro de la política del agua los ecosistemas acuáticos, su conservación y su potencial ecológico, se produce un movimiento diastólico que multiplica la normativa e inmediatamente después un movimiento sistólico que aúna en un único foco de acción toda la normativa anterior o posterior a la DMA (ver figura 1). 
Figura 1. Interrelación de la normativa de la UE en materia de aguas y el WaterBlueprint.
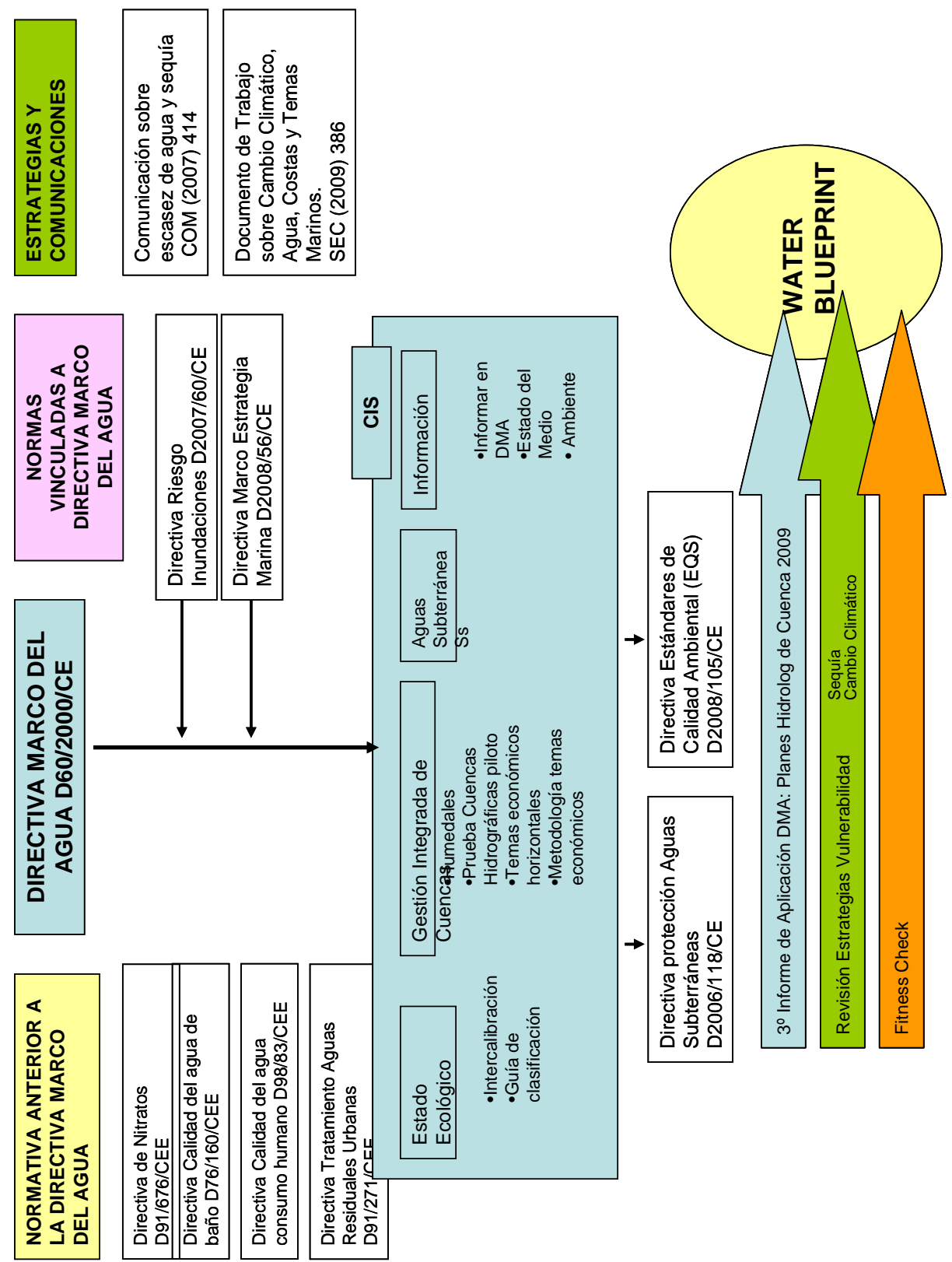

Fuente: Elaboración de Urbano, J \& Commission Staff Working Document SWD(2012) 393 final-Overall process of Blueprint. 


\section{MARCO LEGAL ESPAÑOL}

Sin lugar a dudas, antes de dar comienzo el análisis pormenorizado de la actual Ley de Aguas española, debemos hacer una breve síntesis de las distintas legislaciones nacionales acaecidas en nuestro país desde 1866, año en el que se presentó el primer intento de regulación de las aguas territoriales española, si bien, nunca llegó a entrar en vigor como consecuencia directa del periodo revolucionario que dio lugar a la Primera República Española. A pesar de no entrar nunca en vigor, sentó las bases de la Ley de Aguas de 1879, incluyendo entre sus principios básicos el del dominio público de todas las corrientes naturales, los cauces y riberas de los ríos; todo ello, sin tener en cuenta, las aguas subterráneas. Este precepto continuó en vigor hasta su modificación no retroactiva por la Ley de 1985.

La Ley 29/1985, de 2 de agosto, de Aguas, es el texto básico regulador del dominio público hidráulico y del ejercicio de las competencias atribuidas al Estado en las materias relacionadas con dicho dominio, dentro del marco competencial del art.149.1.1 a de la CE. Dicha Ley de Aguas 29/1985, se ha ido modificando progresivamente en los últimos años, destacando entre ellas la Ley de Aguas 46/1999 y el Texto Refundido de la Ley de Aguas 1/2001. Gracias a esta Ley y a sus correspondientes modificaciones, se ha permitido constatar tanto la existencia de diversos problemas prácticos en la gestión del agua a nivel nacional, como la ausencia en ella de instrumentos eficaces para afrontar las nuevas demandas en relación con dicho recurso, tanto en cantidad, dado que su consumo se incrementa exponencialmente, como en calidad, $\mathrm{y}$, más concretamente, en términos de protección medioambiental.

Cabe destacar que el texto de 1985 estableció un nuevo régimen jurídico del dominio público hidráulico mediante la distribución de competencias entre el Estado y las Comunidades Autónomas, fijando así un marco normativo para todas las Administraciones Públicas competentes. De igual modo, configuró el agua como un recurso unitario renovable a través del ciclo hidrológico (con la pega de que no distinguía entre aguas superficiales y subterráneas) y legalizó un complejo proceso de planificación hidrológica basado en Planes Hidrológicos.

A su vez, en el artículo 16 del Texto Refundido de la Ley de Aguas aprobado por Real Decreto Legislativo 1/2001, se encomienda al Gobierno de la Nación, la fijación del ámbito territorial de las demarcaciones hidrográficas ${ }^{13}$ (que, a su vez, coincidirán con su Plan Hidrológico), los cuales fueron fijados por el Real Decreto 125/2007 (ver figura 2).

\footnotetext{
${ }^{13}$ Incorporación al derecho de aguas español del concepto de demarcación hidrográfica creado por la Directiva 2000/60/CE del Parlamento Europeo y del Consejo de 23 de octubre de 2000 en su artículo 3, por la que se establece un marco comunitario de actuación en el ámbito de la política de aguas.
} 
El concepto de demarcación hidrográfica está recogido, por tanto, en el artículo 16 bis 1 del Texto Refundido de la Ley de Aguas 1/2001 y, se define, como la zona terrestre y marina, compuesta por una o varias cuencas hidrográficas vecinas y las aguas de transición, subterráneas y costeras asociadas a dichas cuencas.

Figura 2. Demarcaciones Hidrográficas Españolas.

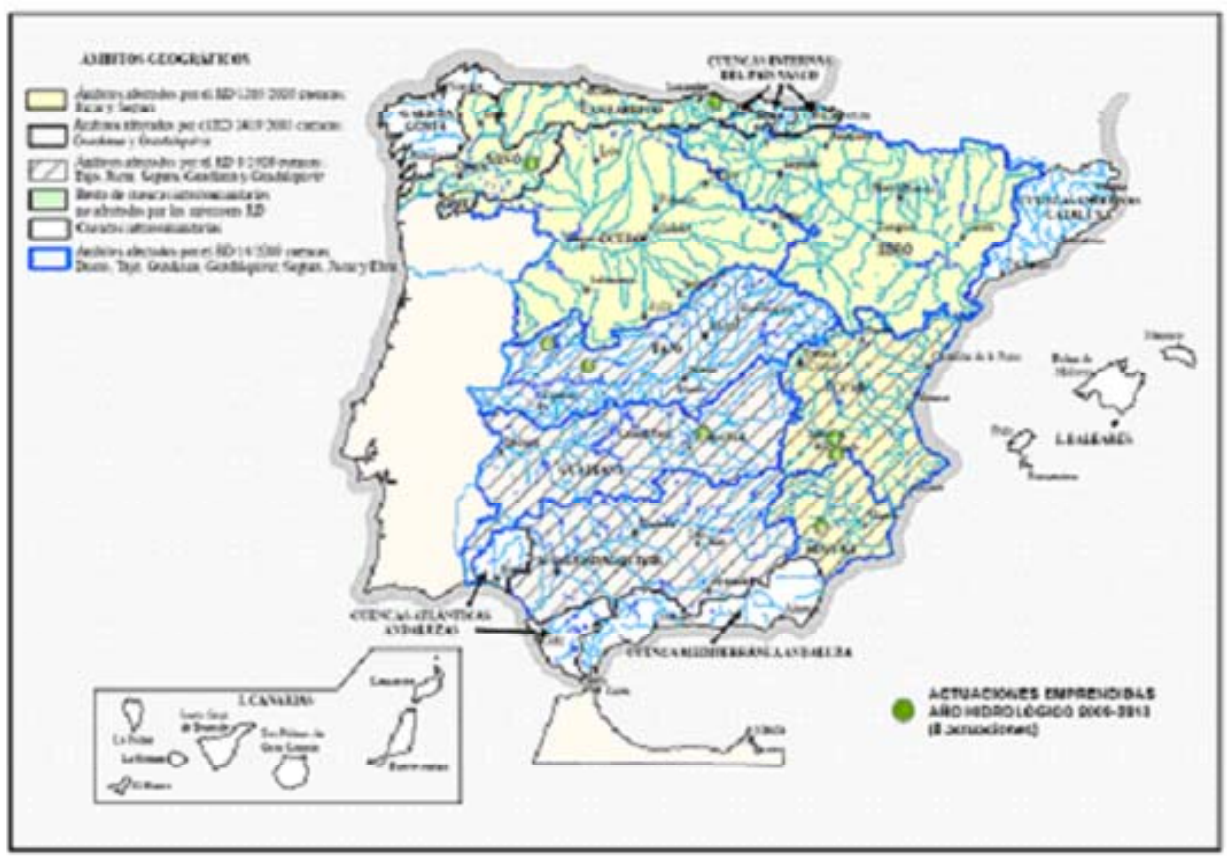

Fuente: Ministerio de Agricultura, Alimentación y Medio Ambiente.

El presente mapa de Demarcaciones Hidrográficas, muestra la división de todas y cada una de las Demarcaciones Hidrográficas, incluida la Demarcación Hidrográfica del Cantábrico Occidental y Oriental establecida por Real Decreto 29/2011. 
Actualmente, en España, existen 19 demarcaciones hidrográficas terrestres que agrupan un total de 138 sistemas de explotación. Siendo los sistemas de explotación: "conjuntos de ríos o tramos de ríos, y unidades hidrogeológicas especialmente interrelacionados". Las demarcaciones hidrográficas territoriales en algunos casos abarcan territorios de una o más Comunidades Autónomas, tal y como podemos ver en el cuadro 3.

Cuadro 3. Clasificación de las Demarcaciones Hidrográficas Españolas.

Demarcaciones hidrográficas Intracomunitarias:

1. Demarcación Hidrográfica de Galicia-Costa.

2. Demarcación Hidrográfica de las Cuencas Internas del País Vasco.

3. Demarcación Hidrográfica de las Cuencas Internas de Cataluña.

4. Demarcación Hidrográfica de las Cuencas Atlánticas de Andalucía.

5. Demarcación Hidrográfica de las Cuencas Mediterráneas de Andalucía.

6. Demarcación Hidrográfica de las Islas Baleares.

7. Demarcaciones Hidrográficas de las Islas Canarias.

DH con cuencas Intercomunitarias situadas en territorio español:

1. Demarcación Hidrográfica del Guadalquivir.

2. Demarcación Hidrográfica del Segura.

3. Demarcación Hidrográfica del Júcar.

DH correspondientes a las cuencas hidrográficas compartidas con otros países:

1. Parte española de la Demarcación Hidrográfica del Miño-Sil.

2. Parte española de la Demarcación Hidrográfica del Cantábrico.

3. Parte española de la Demarcación Hidrográfica del Duero.

4. Parte española de la Demarcación Hidrográfica del Tajo.

5. Parte española de la Demarcación Hidrográfica Guadiana.

6. Parte española de la Demarcación Hidrográfica Ebro.

7. Parte española de la Demarcación Hidrográfica Ceuta.

8. Parte española de la Demarcación Hidrográfica Melilla.

Fuente. Elaboración propia, a partir Hispagua (2012)

Se hace imprescindible definir que los organismos responsables de la gestión de las cuencas hidrográficas, que exceden el ámbito territorial de una sola Comunidad Autónoma, son las Confederaciones Hidrográficas "intercomunitarias". Mientras que, cuando las cuencas hidrográficas están comprendidas en una Comunidad Autónoma se denominan demarcaciones "intracomunitarias", y las responsables de su gestión son las Comunidades Autónomas. 


\section{PLAN HIDROLÓGICO NACIONAL}

El Plan Hidrológico Nacional (PHN), aprobado por la Ley 10/2001, de 5 de julio, $\mathrm{y}$, posteriormente modificado por la Ley 53/2002, de 30 de diciembre, la Ley 62/2003, de 30 de diciembre, el Real Decreto-Ley 2/2004, de 18 de junio, y la Ley $11 / 2005$, de 22 de junio ${ }^{14}$; es un instrumento de planificación, con rango de ley, cuyo objetivo esencial es, según la Ley de Aguas Española ${ }^{15}$, dar respuesta a las cuestiones hidrológicas que sólo pueden abordarse a escala nacional, en ámbitos de análisis y decisión que exceden las cuencas hidrográficas (los excedentes hídricos existentes pueden ser trasvasados hacia zonas donde se presentan desequilibrios hídricos). Por lo tanto, podemos afirmar que se trata de un instrumento ${ }^{16}$ de ordenación, planificación y reequilibrio hídrico orientado al uso sostenible del agua y la recuperación medioambiental del dominio público ${ }^{17}$

Los instrumentos de planificación principales en el Plan Hidrológico Nacional son los Planes de Cuenca ${ }^{18}$, que analizaré más adelante, las cuales operan de forma autonómica en el marco territorial de sus demarcaciones hidrográficas, favoreciendo así el mantenimiento integrado del agua en la propia Cuenca Hidrográfica. .

Cabe destacar que el Plan Hidrológico Nacional no pretende fomentar el uso del agua, incidiendo en la oferta y demanda del recurso hídrico, sino que orienta a corregir los problemas de dotación existentes en las diversas actividades económicas (especialmente en la agricultura) como en el abastecimiento de la población y, para eliminar el problema de la degradación del dominio público hidráulico.

Con lo que los objetivos principales del Plan Hidrológico Nacional son socioeconómicos y medioambientales, orientados hacia el uso sostenible del agua. Entre los objetivos a destacar, establecidos en la Ley de Aguas (artículo 38.1) y el Real Decreto 927/1988 (artículo 70), encontramos;

\footnotetext{
${ }_{15}^{14}$ MARM, 2008a. Plan Hidrológico Nacional.

${ }^{15}$ Art. 38 Ley de Aguas española: "La planificación hidrológica tendrá por objetivos generales conseguir el buen estado ecológico del dominio público hidráulico y la satisfacción de las demandas de agua, el equilibrio y armonización del desarrollo regional y sectorial, incrementando las disponibilidades del recurso, protegiendo su calidad, economizando su empleo y racionalizando sus usos en armonía con el medio ambiente y los demás recursos naturales. Y, la planificación se realizara mediante los planes hidrológicos de cuenca y el plan hidrológico nacional. El ámbito territorial de cada plan hidrológico se determinará reglamentariamente".

${ }_{17}^{16}$ Instrumento de planificación con rango de Ley.

17 Según la Ley de Aguas, el objetivo principal del Plan Hidrológico Nacional es dar respuestas a las cuestiones hidrológicas que sólo pueden abordarse a escala nacional (cuestiones que excedan a las cuencas hidrográficas).

${ }^{8}$ Los Planes de cuenca se concluyeron en 1997, fueron informados favorablemente por el Consejo Nacional del Agua el 27 de abril de 1998, y fueron aprobados por el Consejo de Ministros mediante el Real Decreto 1664/1998, de 24 de julio (BOE num. 191, de 11 de agosto).
} 
a. Resolver las situaciones en las que la grave escasez de recursos hídricos, para;

a.1. Conseguir la mejor satisfacción de las demandas de agua en cantidad, calidad y garantía de suministro con el menor coste posible.

a.2. Incrementar los recursos disponibles mediante nuevas obras de regulación, nuevas captaciones de aguas subterráneas, plantas de recarga artificial de acuíferos, reutilización de aguas residuales depuradas y la desalación para demandas de alta calidad.

a.3. Proporcionar un adecuado nivel de garantía a las explotaciones de regadío ya existentes, de modo que se subsanen las situaciones actuales de precariedad e insostenibilidad.

a.4. Prevenir los estrangulamientos que puede generar la escasez de recursos hídricos sobre otros sectores productivos.

b. Contribuir al uso sostenible de los recursos hídricos, preservando los valores ambientales que se vinculan con el dominio público hidráulico, para;

b.1. Eliminar los problemas de degradación y sobreexplotación de acuíferos y de deterioro del dominio público hidráulico.

b.2. Contribuir a la mejora de los niveles de calidad ambiental de los sistemas hidrológicos y, consiguientemente, de los ecosistemas y paisajes directamente vinculados con ellos.

b.3. Promover el ahorro de agua mediante una política que incentive el ahorro y penalice el despilfarro.

En cuanto a la estructura del Plan Hidrológico Nacional, está conformado por cinco volúmenes, acordes con el programa de actuación a desarrollar:

a. Delimitación y asignación de recursos en acuíferos compartidos

b. Análisis de antecedentes y transferencias planteadas.

c. Análisis de los sistemas hidráulicos.

d. Análisis ambientales.

e. Análisis económicos. 
La formulación del Plan Hidrológico Nacional corresponde, por tanto, a una etapa relativamente avanzada en el proceso de planificación ${ }^{19}$, en la que se constata la imposibilidad de abordar determinados problemas en el ámbito de los planes de cuenca. Ante la importancia social, económica, territorial y ambiental del Plan Hidrológico Nacional, el Ministerio de Medio Ambiente ha estimado conveniente realizar una Evaluación Ambiental Estratégica (EAE) de este Plan, de forma que se proporcionen las mayores garantías respecto a la incorporación de consideraciones ambientales en el Plan.

Cuadro 4. Flujo de información en el proceso de Evaluación Ambiental Estratégica.

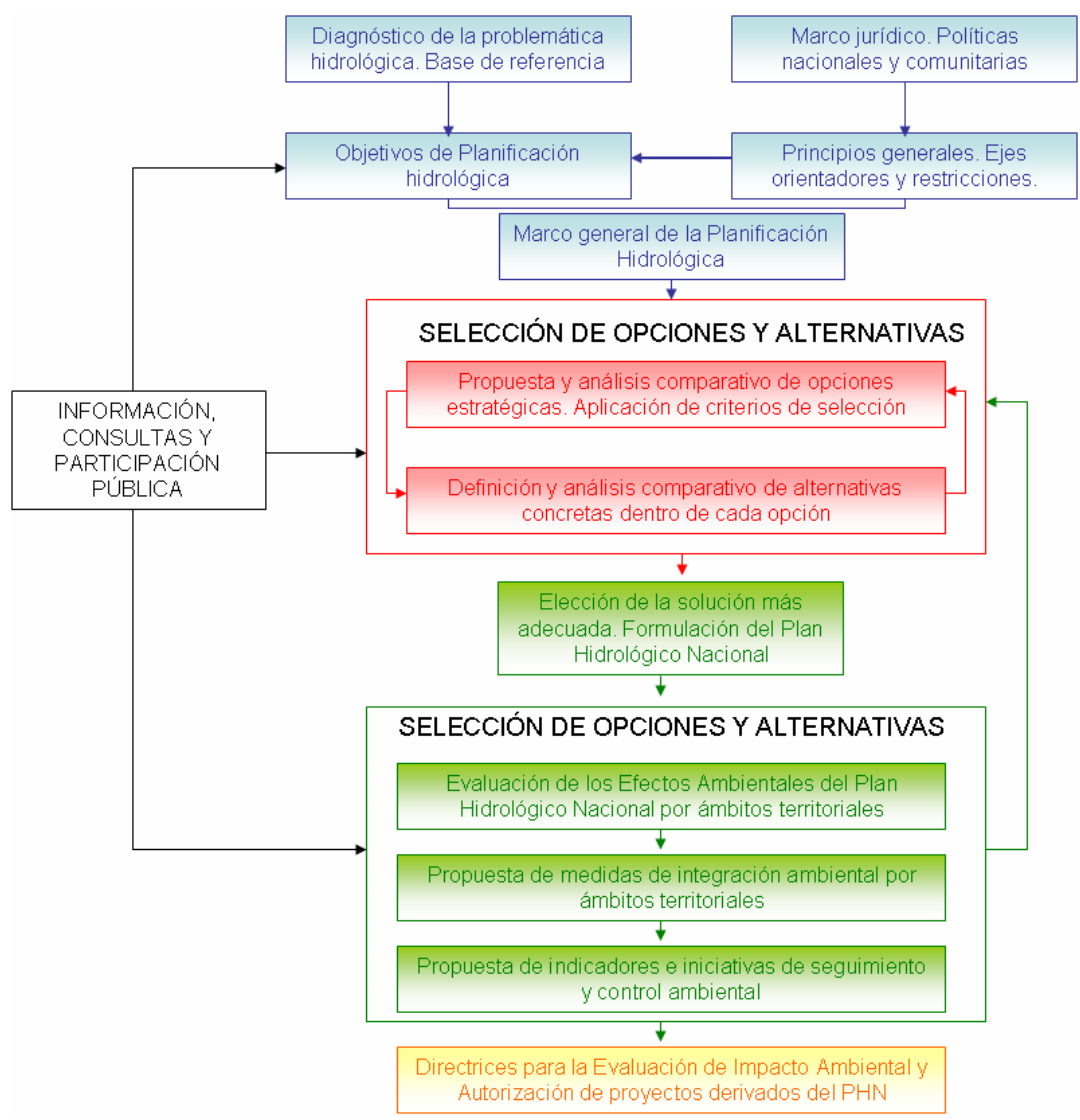

Fuente: Elaboración propia, a partir Ministerio de Agricultura, Alimentación y Medio Ambiente.

${ }^{19}$ Hispagua, (2012). Sistema Español de Información sobre el Agua. 
La Evaluación Ambiental Estratégica ${ }^{20}$ es un instrumento de prevención que prevé integrar los aspectos ambientales en la toma de decisiones de una determinada Política, Plan o Programa, con el objetivo de asegurar que se han tenido en cuenta junto a otros aspectos sociales y económicos, desde las primeras fases del proceso. Por lo tanto, el proceso de planificación hidrológica considera doblemente los aspectos ambientales, tanto como parte de los objetivos a alcanzar en el cumplimiento del buen estado de las masas de agua, como en el marco del proceso de EAE, que se desarrolla paralelamente a la redacción del Plan, junto al desarrollo del Programa de Medidas. En esta línea, se ha iniciado el desarrollo del proceso de Evaluación Ambiental Estratégica del Plan Hidrológico del Júcar, al que se asocia un periodo de consulta y participación pública ${ }^{21}$.

El objetivo del Plan Hidrológico del Júcar debe ser conseguir el buen estado y la adecuada protección del dominio público hidráulico y de las aguas, la satisfacción de las demandas de agua, el equilibrio y armonización del desarrollo regional y sectorial, incrementando las disponibilidades del recurso, protegiendo su calidad, economizando su empleo y racionalizando sus usos en armonía con el medio ambiente y los demás recursos naturales. El Plan incluirá, entre otros aspectos los objetivos medioambientales para las masas de aguas, los programas de medidas y alternativas para alcanzar los objetivos.

De igual modo, las actuaciones previstas en el Plan Hidrológico Nacional incluyen la modernización de regadíos, regulación de cuencas fluviales, abastecimientos urbanos, saneamiento y depuración de aguas residuales, acondicionamiento de cauces y prevención de avenidas, programa de control y mejora de la calidad de las aguas superficiales y subterráneas, regeneración hidrológicoforestal.

El análisis de los diferentes planteamientos del último Plan nos aproxima a distintas posibilidades de interpretación; a saber:

\section{a. Ventajas:}

1. Retoma un tema «tabú» en el modelo de desarrollo español.

2. Pone las bases para el estudio y valoración de un ulterior "Plan Hidrológico Nacional"

3. Se plantea la necesidad de buscar el equilibrio entre la conservación del agua y de los ecosistemas asociados (ríos, lagos, deltas marismas...), muy castigados por la política hidráulica tradicional, basada en el hormigón.

\footnotetext{
${ }^{20}$ La Ley 9/2006,de 28 de abril, sobre evaluación de los efectos de determinados planes y programas en el medioambiente (BOE $\mathrm{n}^{\circ} 102$ de 29 de abril de 2006) regula la aplicación de la Evaluación Ambiental Estratégica en su transposición al ordenamiento jurídico español

${ }^{21}$ Sotelo, J.A. et alii (2010).
} 
4. Se acerca a las necesidades reales de la población.

5. Intenta aproximarse a la función social del agua, superando los postulados meramente económicos, amén de solucionar los distintos problemas emanados de su contaminación.

b. Desventajas:

1. El Plan beneficia, claramente, a las empresas constructoras, encargadas "a posteriori”, de ejecutar el centenar de embalses, más los trasvases propuestos.

2. Carece en líneas generales de credibilidad, pues no responde a la política hidráulica propuesta hasta el momento, incluso por los últimos Gobiernos (v.gr.: el Libro Blanco del Agua).

3. No da respuesta a la resolución de problemas como los emanados de la salinización de los acuíferos costeros (Cataluña, Andalucía, Baleares, Canarias...). Todo ello unido a que en el Plan no se dedica ni una sola línea al tema de la "desalación".

4. El almacenamiento, canalización y transporte del agua, de una zona a otra del país, propuestos por el Plan, no tiene nada que ver con una verdadera gestión del agua (ésta debería basarse, principalmente, por criterios marcados por la escasez de este recurso).

5. En un país como el nuestro, en el que más del ochenta por ciento del agua es consumida por el sector agrícola, debería aprobarse — se está intentandoprimero el Plan Nacional de Regadíos, después el Plan Hidrológico Nacional.

\section{LAS CONFEDERACIONES HIDROGRÁFICAS Y LOS PLANES HIDROLÓGICOS POR CUENCAS}

Un organismo de cuencas, también denominado Confederación Hidrográfica, es una entidad de Derecho Público con personalidad jurídica propia que actúa como unidad administrativa y operativa para la gestión sostenible de la cuenca hidrográfica, organizada con la participación interinstitucional y representativa de los actores clave, que tienen responsabilidades, intereses o actúan en una cuenca. A efectos administrativos está adscrita al Ministerio de Agricultura, Alimentación y Medio Ambiente. En cuanto a la organización de las Confederaciones, la administración pública del agua se ejerce en las cuencas intercomunitarias, mientras que las cuencas intracomunitarias son legisladas por las administraciones Hidráulicas de las 
Comunidades Autónomas correspondientes. Lo que denota que la unidad territorial del organismo, es la "cuenca hidrográfica" (formado por conjunto de cuencas, cuenca, subcuenca, microcuenca o quebradas), en el cual el sistema hídrico determina sus límites físicos.

Debemos tener en cuenta que "la cuenca" es un territorio estructurado bajo un sistema integral ${ }^{22}$; su unidad es definida por la naturaleza y sobre ella ocurren otras delimitaciones para administrar recursos o actividades económicas y sociales. Sin embargo, cuando se trata de definir de quién es la responsabilidad del manejo de la cuenca, no es fácil encontrar una competencia legal, institucional y funcional. En forma particular para cada uno de los recursos agua, suelo o bosque generalmente existen marcos legales que definen la competencia de cómo manejar, utilizar, aprovechar o conservar tal recurso, así mismo sobre los territorios municipales también existen responsabilidades y competencias definidas, es más, los recursos provenientes del estado son otorgados a este nivel Administrativo en las nuevas estrategias de descentralización.

La descentralización de la gestión del agua en España, surge a partir de 1926, adaptándose territorialmente al nivel de cuenca. Las competencias sobre el dominio público hidráulico las ejerce directamente el Estado a través de las Confederaciones Hidrográficas.

De acuerdo con la Ley de Aguas 29/1985, las funciones de las confederaciones hidrográficas $\operatorname{son}^{23}$ : la elaboración, seguimiento y revisión del Plan Hidrológico de cuenca, la administración y control del dominio público hidráulico, otorgando autorizaciones y concesiones y vigilando el cumplimiento de las mismas; el proyecto, construcción y explotación de las obras realizadas con fondos propios y las que le sean encomendadas por el Estado u otros entes territoriales; y cualquier otra función que emane del acuerdo de la confederación con otros entes públicos o privados.

${ }^{22}$ Dourojeanni, A. et alii (2002) Gestión del Agua a nivel de Cuencas: Teoría y práctica. CEPAL, Chile.

${ }^{23}$ De acuerdo con el artículo 23 del Texto Refundido de la Ley de Aguas 1/2001:

a. La elaboración del Plan Hidrológico de cuenca, su seguimiento y revisión.

b. La administración y control del Dominio Público Hidráulico.

c. La administración y control de los aprovechamientos de interés general o que afecten a más de una Comunidad Autónoma.

d. El proyecto, la construcción y explotación de las obras realizadas con cargo a los fondos propios del Organismo, y las que les sean encomendadas por el Estado.

e. Las que se deriven de los convenios con Comunidades Autónomas, Corporaciones Locales y otras Entidades públicas o privadas, o de los suscritos con los particulares. 
Cuadro 5. Planes Hidrológicos en vigor en las Confederaciones Hidrográficas.

\begin{tabular}{|c|c|c|c|}
\hline Plan Hidrológico & Confederación Hidrográfica & Comunidades Autónomas Comprendidas & Aprobación \\
\hline $\begin{array}{l}\text { PH del Norte I } \\
\text { PH del Norte II }\end{array}$ & $\mathrm{CH}$ del Miño-Sil & Castilla y León, Asturias y Galicia & \multirow{10}{*}{$1664 / 1998$} \\
\hline $\begin{array}{l}\text { PH del Norte II } \\
\text { PH del Norte III }\end{array}$ & $\mathrm{CH}$ del Cantábrico & $\begin{array}{c}\text { Asturias, Cantabria, Castilla y León, Navarra, } \\
\text { Galicia y País Vasco }\end{array}$ & \\
\hline PH del Duero & $\mathrm{CH}$ del Duero & Castilla y León, y Galicia & \\
\hline PH del Tajo & $\mathrm{CH}$ del Tajo & $\begin{array}{c}\text { Aragón, Castilla-La Mancha, Castilla y León, } \\
\text { Extremadura y Madrid }\end{array}$ & \\
\hline $\begin{array}{l}\text { PH del Guadiana I } \\
\text { PH del Guadiana II }\end{array}$ & $\mathrm{CH}$ del Guadiana & Castilla-La Mancha, Andalucía y Extremadura & \\
\hline PH del Guadalquivir & $\mathrm{CH}$ del Guadalquivir & Andalucía, Castilla-La Mancha, Murcia y Extremadura & \\
\hline PH del Sur & Agencia Andaluza del Agua & & \\
\hline PH del Júcar & CH del Júcar & Cataluña, C.Valenciana, Aragón, Castilla-La Mancha y Murcia. & \\
\hline PH del Ebro & $\mathrm{CH}$ del Ebro & $\begin{array}{l}\text { Castilla y León, Cantabria, País Vasco, Rioja, Navarra, } \\
\text { Aragón, Castilla-La Mancha, C. Valenciana y Catalña }\end{array}$ & \\
\hline Cuencas Internas de Cataluña & Agencia Catalana del Agua & & \\
\hline PH de las Islas Baleares & Gobierno Islas Baleares & & $378 / 2001$ \\
\hline PH de Galicia Costa & Aguas de Galicia & & $103 / 2003$ \\
\hline
\end{tabular}

Fuente: Elaboración propia, a partir de MARM (2008).

\section{ESTRATEGIA ESPAÑOLA DE DESARROLLO SOSTENIBLE}

La Unión Europea cuenta, desde el año 2001, con una Estrategia de Desarrollo Sostenible, fundamentado en la sostenibilidad económica, ecológica y social ${ }^{24}$. Dicha estrategia fue revisada en el año 2006 y pretende interrelacionar los componentes de la sostenibilidad en su triple dimensión. En los primeros años tras su aprobación se realizaron importantes reformas en su política agraria y pesquera, se puso en marcha un sistema de comercio de derechos de emisión y, estableció los mecanismos adecuados para la realizar Evaluaciones de Impacto Ambiental con el fin de analizar las medidas estipuladas en pro del desarrollo sostenible. A pesar de todo ello, se siguieron registrando tendencias no sostenibles en relación con el cambio climático, el uso de la energía, la salud pública, la pobreza, la exclusión social, la perdida de biodiversidad, la mala gestión de los recursos naturales...

Por todo ello, tras su revisión en el año 2006, se ampliaron los objetivos y su acción se estructuró entorno a siete áreas prioritarias ${ }^{25}$ :

\footnotetext{
${ }^{24}$ Un principio general de la Estrategia de Desarrollo Sostenible, consistente en "determinar y elaborar medidas que permitan mejorar continuamente la calidad de vida para las actuales y futuras generaciones mediante la creación de comunidades sostenibles capaces de gestionar y utilizar los recursos de forma eficiente, para aprovechar el potencial de innovación ecológica y social que ofrece la economía, garantizando la prosperidad, la protección del medio ambiente y la cohesión social”.

${ }^{25}$ Estrechamente vinculados a los propios Objetivos del Desarrollo del Milenio, establecidos en el año 2000 con miras a 2015, firmados por 193 países miembros de la Naciones Unidas.
} 
1. Cambio climático y energías limpias; Con el fin de reducir dicho "cambio climático", disminuyendo tanto sus efectos negativos como sus costes tanto en términos económicos como sociales $\mathrm{y}$, por ende, ambientales.

2. Transporte sostenible; Favorecer un transporte de calidad, enfocado a la reducción al mínimo posible de sus efectos negativos sobre la sostenibilidad de los países.

3. Producción y consumo sostenibles; Favorecer el consumo sostenible

4. Retos de la salud pública; Fomentar una buena salud pública más igualitaria.

5. Gestión de recursos naturales (dentro del que se encuentra el Agua); Evitar la sobreexplotación de los recursos naturales en pro del buen sostenimiento de los ecosistemas.

6. Inclusión social, demografía y migración; Solidaridad intra e intergeneracional y asegurar una mejor calidad de vida de los ciudadanos; $\mathrm{y}$,

7. Lucha contra la pobreza mundial.

Para poder llevar acabo las distintas actuaciones recogidas en las distintas áreas prioritarias se estipuló que cada Estado Miembro asumiera sus propios compromisos de desarrollo sostenible plasmados en sus respectivas Estrategias Nacionales de Desarrollo Sostenible que serían objeto de revisión por parte de la Comisión y por el resto de los Estados.

De este modo surgió la actual Estrategia Española de Desarrollo Social (EEDS), la cual tiene un planteamiento acorde con la visión estratégica de la UE, favoreciendo un desarrollo sostenible global entre la triple dimensión, económica, ecológica y social, que lo define, con los objetivos principales de:

1. Garantizar la prosperidad económica;

2. Asegurar la protección del medio ambiente;

3. Evitar la degradación del capital natural;

4. Fomentar una mayor cohesión social teniendo en cuenta las tendencias demográficas actuales y contribuir solidariamente al desarrollo de los países menos favorecidos en aras de la sostenibilidad global.

Al analizar cada uno de los componentes sobre los que se desarrolla la Estrategia Española de Desarrollo Sostenible (EEDS), observamos que, en el apartado de Sostenibilidad Ambiental se incluye como una prioridad, la conservación y gestión de los recursos naturales y ocupación del territorio (Ministerio de la Presidencia, 2007). En términos de sostenibilidad ambiental, se establecen líneas de actuación enfocadas a la protección y conservación del aire, del agua, del suelo, de la naturaleza y de la salud; mediante el control de la producción vs. consumo, la gestión y conservación de los recursos naturales y, la ocupación del territorio.

Debemos destacar que el recurso hídrico es uno de los principales ámbitos de actuación, estableciendo como objetivo: asegurar la sostenibilidad ambiental y la 
calidad del recurso hídrico, garantizando el abastecimiento a la población y el uso productivo sostenible del mismo dentro del marco de la Directiva Marco del Agua (DMA). Actualmente, las actuaciones previstas en la EEDS, que se están llevando a cabo o que están previstas de realizar, en materia medioambiental, son:

1. Gestión de la demanda y de conservación y restauración de los recursos hídricos: Las principales actuaciones estratégicas se encuadran dentro del Programa Global de Actuaciones para la Gestión y Utilización del Agua (Programa A.G.U.A.), e incluyen la depuración de aguas residuales, la regeneración y reutilización de las aguas, la mejora y modernización de sistemas de abastecimiento y de riego y, la construcción de plantas desaladoras.

2. Recuperación y gestión medioambiental: Se busca asegurar la calidad de las aguas y la recuperación y gestión ambiental de los ríos.

2.1. Para asegurar la calidad de las aguas se ha establecido el Plan Nacional de Calidad de las Aguas: Saneamiento y Depuración 2007-2015, como nuevo mecanismo de gestión, cooperación y coordinación institucional y de solidaridad interregional entre Administraciones competentes en la gestión del recurso hídrico.

2.2. Para la recuperación y gestión ambiental de los ríos, se ha establecido el Plan Nacional de Restauración de Ríos y el Plan de Conservación y Mejora del Dominio Público Hidráulico.

3. Reutilización y desalación: Se busca fomentar la utilización de las aguas regeneradas en actividades como la agricultura, riego de parques y jardines, campos de golf, mantenimiento de caudales medioambientales, etc.

4. Uso sostenible de las aguas subterráneas: Se persigue la mejora del conocimiento y del control de las aguas subterráneas, la ordenación de la explotación mediante la regulación legal de las extracciones en las masas en riesgo, la reducción paulatina de la contaminación y su prevención, la construcción de captaciones de recarga artificial de acuíferos para situaciones de emergencia por sequía, y la integración de su explotación con la de los recursos superficiales.

5. Sequías e inundaciones: Estableciendo un conjunto de planes, programas, directivas y proyectos que favorezcan la prevención de desastres naturales vinculados a las sequías e inundaciones.

a. Planes Especiales de Alerta y Actuación.

b. Directiva de Inundaciones.

b.1. Evaluación preliminar del riesgo de inundación (2011).

b.2. Mapas de peligrosidad y riesgo de inundaciones (2013). 
b.3. Planes de gestión del riesgo de inundación (2015).

c. Sistema Nacional de Cartografía de Zonas Inundables.

c.1. Incluye las medidas del Plan Nacional de Restauración de Ríos

c.2. Integrará la cartografía de los Organismos de cuenca, las CC.AA., Protección Civil y demás entidades involucradas.

Con todo ello, y de acuerdo a la Directiva 91/271/CEE, para cuantificar la consecución de los objetivos se utilizarán como indicadores el índice de calidad general de las aguas y los índices de llenado de los acuíferos y de riesgo de sequía por cuencas hidrográficas.

Por último, concluir el punto analizando la petición por parte de la Comisión (solicitada por el Consejo Europeo de diciembre de 2007), en junio de 2009 un informe de evolución de la Estrategia en estos últimos años ${ }^{26}$. En el informe se confirma que algunas políticas europeas han logrado avances positivos en las distintas áreas temáticas recogidas en la Estrategia. Entre estas políticas se encuentran: el paquete de medidas sobre cambio climático y energía de diciembre de 2008, las medidas en favor de sistemas de transporte más inteligentes y ecológicos, la mejora de la eficiencia energética de los edificios, las revisiones de las directivas sobre el diseño ecológico y la etiqueta ecológica, el establecimiento de un marco integrado para la política marítima y una estrategia sanitaria de la UE, el trabajo en materia de inmigración y la lucha contra la pobreza y la exclusión. Sin embargo, en algunos sectores persisten tendencias insostenibles, la demanda de recursos naturales sigue una tendencia creciente, se está perdiendo biodiversidad y sigue aumentando el consumo de energía del sector del transporte.

\section{PROGRAMA A.G.U.A.}

El agua es un derecho universal que posee un valor intrínseco económico, social y ambiental. Con lo que, amén de ser un derecho también es una responsabilidad. La demanda y, por ende, su consumo ha de ser sostenible y, la gestión de la misma por parte de los poderes públicos ha de ser racional, ética, equitativa... evitando el abuso y la degradación de este bien tan preciado. Con todas estas premisas surge el Programa A.G.U.A. en el año 2007.

El Programa A.G.U.A. (Actuaciones para la Gestión y la Utilización del Agua) se creó para resolver gradualmente las carencias en la gestión, en la disponibilidad y en la calidad del agua, presentes en toda España, en particular en las cuencas mediterráneas, con soluciones duraderas y responsables. De igual modo, tiene el objetivo de materializar la reorientación de la política del agua, mediante la difusión de las actuaciones concretas diseñadas para garantizar la disponibilidad y la calidad

\footnotetext{
${ }^{26}$ Red Ambiental de Asturias. Gobierno del Principado de Asturias. Principios de la Directiva Marco del Agua. http://www.asturias.es
} 
del agua en cada territorio. A su vez, permite a todos los ciudadanos conocer y comprender mejor la política del agua, para actuar así de forma más responsable y exigente, aportando incluso sugerencias y propuestas al Ministerio de Medio Ambiente.

El programa A.G.U.A. se aplica en toda España, y tuvieron como primera zona de actuación las cuencas mediterráneas (Cuencas Hidrográficas del Sur, Segura, Júcar, Ebro y Cuencas Internas de Cataluña), por los problemas que presentan. El Programa A.G.U.A. se caracteriza por incorporar actuaciones que históricamente fueron propuestas pero que en la práctica no fueron desarrolladas, que son coherentes con los objetivos del Programa, y que, por su viabilidad económica y ambiental son susceptibles de obtener financiación europea. También, incorpora un conjunto de nuevas actuaciones dirigidas a la optimización y mejora de la gestión del agua, a la generación de nuevos recursos, a la prevención de inundaciones y a la depuración y reutilización de agua. Y como un aspecto esencial de este programa, se apuesta por la participación social, por lo que la concertación de nuevas actuaciones está abierta a las sugerencias de los ciudadanos, pudiendo modificarse o ampliarse el Programa con las aportaciones que se introduzcan en el debate parlamentario.

De igual modo, junto al Plan Hidrológico Nacional, el Programa A.G.U.A. propone abastecer al levante español mediante la construcción de desaladoras y elimina el trasvase del Ebro, fomentar la participación popular y las Comunidades Autónomas en la gestión del agua realizada por las Cuencas Hidrográficas.

Por ello, las actuaciones inversoras que se han puesto en marcha para incrementar la disponibilidad de los recursos hídricos en las cuencas mediterráneas, muestran que la provincia en la que se debe aumentar en mayor medida la disponibilidad de recursos hídricos es Almería ( $165 \mathrm{hm}^{3} /$ año), porque presenta mayores condiciones de sequía. Otras provincias con importantes actuaciones para incrementar la disponibilidad de agua son Alicante $\left(141 \mathrm{hm}^{3} /\right.$ año $)$ y Murcia $\left(140 \mathrm{hm}^{3} /\right.$ año$)$. Valencia es la provincia que menos debe incrementar la disponibilidad de recursos hídricos (3 $\mathrm{hm}^{3} /$ año) y la que mejor gestiona los recursos hídricos $\left(107 \mathrm{hm}^{3} /\right.$ año). En Tarragona únicamente se pondrán en marcha actuaciones dirigidas a la mejora de la calidad del agua, prevención de inundaciones y restauración ambiental.

\section{A MODO DE CONCLUSIONES}

La experiencia española en términos de legislación del recurso hídrico es especialmente interesante, puesto que sus tres niveles de gobierno, el central, el regional y el local -amén del régimen legislativo internacional-, tienen competencias en materia de conservación y preservación ambiental del agua. $\mathrm{Y}$ es que, el deterioro del medio ambiente a través de la contaminación de las aguas, de forma concreta, es tan grave e intenso como sutil. En tan sólo unos años, buena parte de la red hidrológica de los países desarrollados podemos afirmar que se está convirtiendo en auténticas cloacas a cielo abierto.

Por todo ello, a la hora de tratar la gestión compleja del recurso hídrico en España debemos tener en cuenta que existe una gran variedad de legislaciones que regulan y 
gestionan el abastecimiento, depuración y consumo del agua. El Marco Institucional de la gestión del agua en España, se conforma por entes de carácter público y privado que interactúan con el fin primario de abastecer de bienes y servicios relacionados con el recurso hídrico para, de este modo, satisfacer las necesidades ilimitadas de la población.

El cuerpo normativo sobre la política europea del agua se ha visto fuertemente incrementado a partir de 2006; y es que, la proliferación de actos se refiere a un esfuerzo universalizador e integrador, propio del enfoque ecosistémico. Desde esta perspectiva, podemos hablar de un antes y un ahora de la "Directiva Marco del Agua".

En España, la descentralización de la gestión del agua en España, surge a partir de 1926, adaptándose territorialmente al nivel de cuenca. A través de los Planes Hidrológicos como instrumentos de planificación con rango de ley, se pretende dar respuesta a las cuestiones hidrológicas que sólo pueden abordarse a escala nacional, en ámbitos de análisis y decisión que exceden las cuencas hidrográficas (los excedentes hídricos existentes pueden ser trasvasados hacia zonas donde se presentan desequilibrios hídricos). Por lo tanto, podemos afirmar que se trata de un instrumento de ordenación, planificación y reequilibrio hídrico orientado al uso sostenible del agua y la recuperación medioambiental del dominio público. Las competencias sobre el dominio público hidráulico las ejerce directamente el Estado a través de las Confederaciones Hidrográficas.

De igual modo, los Ayuntamientos y Entidades Locales son fundamentales en la gestión del agua, sobre todo en lo referente a la prestación de servicios finales a los usuarios como es el abastecimiento de agua potable, el saneamiento y la depuración. Sin embargo, en los últimos años, esta gestión no sólo dependen de la Administración Pública sino que el sector privado participa de dicha actividad - prestar servicios finales a los usuarios- mediante concesiones administrativas.

$Y$ es que, el agua es un derecho universal que posee un valor intrínseco económico, social y ambiental; con lo que, amén de ser un derecho también es una responsabilidad. Por ello, se creó el Programa A.G.U.A. (Actuaciones para la Gestión y la Utilización del Agua), con el fin de resolver gradualmente las carencias en la gestión, en la disponibilidad y en la calidad del agua, presentes en toda España; de reorientar la política del agua, mediante la difusión de las actuaciones concretas diseñadas para garantizar la disponibilidad y la calidad del agua en cada territorio; y, permitir a todos los ciudadanos conocer y comprender mejor la política del agua, para actuar así de forma más responsable y exigente, aportando incluso sugerencias y propuestas al Ministerio de Medio Ambiente.

Por último, señalar como una cuestión importante como la Unión Europea cuenta, desde el año 2001, con una Estrategia de Desarrollo Sostenible, que pretende interrelacionar los componentes de la sostenibilidad en su triple dimensión (económica, ecológica y social). Todo ello con el fin de gestionar la demanda, la conservación, la recuperación y restauración de los recursos hídricos, en particular, y del medio ambiente, en general.

En definitiva, en nuestra investigación se pone de manifiesto como una amplia, a la par que consolidada, legislación en materia de recursos hídricos nos aproxima cada 
vez más a un desarrollo sostenible del medio ambiente de nuestro país, consolidando así las bases de una mejor calidad del medio natural sobre las que asentar nuestra futura calidad de vida.

\section{BIBLIOGRAFÍA}

ESTRATEGIA DE DESARROLLO SOSTENIBLE (2007). Ministerio de la Presidencia. M-54376-2007

EUROPEAN COMMISSION (2012): "Commission Staff Working Document. The Fitness Check of EU Freshwater Policy" Brussels. SWD(2012) 393 final.

EUROPEAN ENVIRONMENT AGENCY, EEA, (2012): "Toward and efficient use of water resources in Europe". EEA report 1/2012. Copenhagen. Denmark.

DIRECTIVA MARCO DEL AGUA, Directiva 60/2000/CE.

FUNDACIÓN NUEVA CULTURA DEL AGUA, FNCA. (2014): Guía Nueva Cultura del Agua. Online: http://www.fnca.eu/guia-nueva-cultura-del-agua/laplanificacion-y-gestion-del-agua-en-espana

HISPAGUA, Sistema Español de Información sobre el Agua (2006): "Huella Hídrica" de las Naciones.

HISPAGUA, Sistema Español de Información sobre el Agua (2010): Confederaciones Hidrográficas.

LA CALLE MARCOS, A. (2009) La adaptación española de la Directiva Marco del Agua. Fundación Nueva Cultura del Agua. Sevilla.

LA-ROCA, F. (2008): El desarrollo de la Directiva Marco del Agua y los nuevos instrumentos económicos en la gestión del agua. Fundación Nueva Cultura del Agua. Convenio Universidad de Sevilla y Ministerio de Medio Ambiente. Sevilla.

LEY DE AGUAS ESPAÑOLA, 29/1985, de 2 de agosto.

MAESTU, J. Y VILLAR,A. (2006): "El sector de los servicios del agua en España: "Recuperación de costes y perspectivas financieras". Revista Ambienta (Octubre, 2006). MIMAM. Madrid.

MINISTERIO DE MEDIO AMBIENTE (2000). Libro Blanco del Agua. Centro de Publicaciones, Secretaría general Técnica, Ministerio de Medio Ambiente.

MINISTERIO DE MEDIO AMBIENTE. (2001). Evaluación Ambiental Estratégica del Plan Hidrológico Nacional. Ministerio de Medio Ambiente. Madrid.

OECD (2012) "A Framework for Financing Water Resources Management. OECD Studies on Water". OECD Publishing. Paris. France.

OLCINA CANTOS, J. y MOLTÓ MANTERO, E. (2010): "Recursos de agua no convencionales en España. Estado de la cuestión, 2010" Investigaciones Geográficas, 51. Instituto Universitario de Geografía, Universidad de Alicante, pp. 131-163.

PROGRAMA A.G.U.A. http://www.mma.es/secciones/agua/entrada.htm

PORTA, F. (2001): La Directiva Marco del Agua: aplicación del principio de recuperación de los costes en el sector urbano del agua en España, en "La DMA y sus implicaciones para la gestión del agua en España”. CENTA. Sevilla. 
RED AMBIENTAL DE ASTURIAS. Gobierno del Principado de Asturias. Principios de la Directiva Marco del Agua. http://www.asturias.es

REGLAMENTO DEL DOMINIO PÚBLICO HIDRÁULICO, REAL DECRETO 849/1986, de 11 de abril.

RICO GONZÁLEZ, M. y GÓMEZ-LIMÓN RODRÍGUEZ, J.A. (2002). ¿Funconarán los Mercados de Agua en España?

RICO GONZÁLEZ, M. y GÓMEZ-LIMÓN RODRÍGUEZ, J.A. (2005). Los mercados del agua: análisis de los condicionantes para su correcto desarrollo en España. Estudios Agrosociales y Pesqueros, n 206. Pp. 33-62.

ROSEMBUJ, T. (1995). Los tributos y la protección del medio ambiente. Marcial Pons.

SOTELO NAVALPOTRO, J.A. (2001). Estudiar la Región. Infodal, pp.285.

SOTELO NAVALPOTRO, J.A. (2001). Environmental Europe. Oxford University Press, pp. 195

SOTELO NAVALPOTRO, J.A. (2006). Bases territoriales de la planificación integral. El estudio de caso: La Cuenca del Tajo. Madrid. Revista de Arte, Geografía e Historia, no 8. pp. 359 - 396.

SOTELO, J.A. (2009). "Las lógicas ilógicas del agua". Tribuna Complutense. pp.4.

SOTELO, J.A. et alii. (2010). "La "Huella Hídrica" española en el contexto del cambio ambiental". Fundación Mapfre. Madrid. 218pp.

SOTELO, J.A. et alii. (2011). "La "Huella Hídrica" española en el contexto del cambio ambiental". Fundación Mapfre. Madrid.

SOTELO PÉREZ, M. y SOTELO PÉREZ, I. (2013). Desarrollo y medioambiente en España. Instrumentos económicos de la Ley de Aguas. I Seminario Internacional de Manejo Sostenible de Suelos Agrarios y de Recursos Naturales, ISBN 978-8415487-75-3. Ed. Universidad de Almería.

SUMMER, L. H. (1991). The case for corrective taxation, National Tax Journal, 44: 289-292.

TEXTO REFUNDIDO DE LA LEY DE AGUAS, REAL DECRETO LEY 10/2001, de 20 de julio.

TEXTO REFUNDIDO DE LA LEY DE HACIENDAS LOCALES, Real Decreto $2 / 2004$, de 5 de marzo

TEXTO REFUNDIDO DE LA LEY DE CONTRATOS DEL SECTOR PÚBLICO, Real Decreto Legislativo 3/2011.

VÁZQUEZ, C. (2004). La fiscalidad de las aguas en España. En Tributación medioambiental: Teoría, práctica y propuestas. Civitas. Madrid. Pp. 147 - 184.

URBANO LÓPEZ DE MENESES, J. (2014): El "Water Blueprint" y su influencia en la agricultura española, Observatorio Medioambiental, vol. 16.

YÁBAR STERLING, A et alii. (2012). Green Taxation and Environmental Sustainability. Critical Issues on Environmental Taxation. Volumen XII pp. 283

YABAR STERLING, A. (2013). "El papel de los tributos en el modelo español de gestión regional del buen estado ecológico de las masas de agua". Instituto de Estudios Fiscales. (España) 1-18 pp. 